\title{
La critica de arte y la construcción del patrimonio cultural. Buenos Aires 1931
}

\author{
MARIA VICTORIA STREPPONE \\ Università Ca Foscari Venezia
}

Recibido: 11-05-2019

Aprobado: 26-10-2019

\section{RESUMEN}

Este trabajo se centra en una "constelación"de intelectuales argentinos de horizontes inevitablemente eurocentricos que, mediante la propia contribución ofrecida en la revista Sur (19311992) a través de ensayos sobre crítica de arte, intentan comprender las dificultades del momento artístico local. Con el inicio de una secuencia de eventos, se propone una reflexión que entiende el cine y la arquitectura como un “espacio pedagógico". Por medio del análisis y la interpretación del papel cultural de Victoria Ocampo (Buenos Aires 1890-1979) y la "herramienta-revista" Sur, se presentan una serie de eventos y estrategias unidos por un fil rouge orientado a crear la unidad cultural argentina; desde el apoyo personal y privado, brindado a Le Corbusier durante su viaje por Argentina y el proyecto documental que inicia en el marco del cine sovietico de Sergej Ėjzenštejn hasta abarcar el neorrealismo italiano de Vittorio De Sica y Cesare Zavattini.

El enfoque en Ocampo, escritora, mecenas y directora de Sur, lleva el análisis crítico al marco moderno de los estudios de género, abriendo -a la cultura y sociedad argentina de los años en cuestión- un panorama de ideas complejo y fructífero, respecto al horizonte de desarrollo del propio patrimonio cultural.

PALABRAS CLAVE: patrimonio cultural argentino /crítica de arte / constelación Victoria Ocampo / "Sur"/ vertigine orizzontale.

\section{ABSTRACT}

This paper focuses on a "constellation" of argentinian scholars characterized by an inevitable and common eurocentric horizon that, through their own contribution in Sur (19311992) with several art critic essays, try to interpretate the tough local artistic moment. Starting from a sequence of events, a reflection on cinema and architecture as a 'pedagogical space', is proposed. Through the analysis and interpretation of Victoria Ocampo's cultural role and her tool-magazine named Sur, a series of events and strategies connected by a fil rouge oriented to create an Argentian cultural unity are presented: from the personal and private support provided to Le Corbusier during his journey to Argentina and the documentary project that starts in the framework of the Soviet cinema of Sergej Ejzenštejn, to the Italian neorealism of Vittorio De Sica and Cesare Zavattini. 
The focus in Ocampo, writer, maecenas and director of Sur brings critical analysis to the modern framework of gender studies, opening - to the Argentine culture and society of those years - a complex and fruitful panorama of ideas, to the horizon of development of one's cultural heritage.

KEY WORDS: Argentine cultural heritage/art critic/Victoria Ocampo constellation / "Sur" / vertigine orizzontale.

\section{Introducción}

Cuando en 1931 aparece en Argentina el primer número de la revista Sur, Victoria Ocampo escribe «La aventura del mueble» ${ }^{1}$ : primer tentativo de reflexión sobre las condiciones del tipo de arquitectura y de los objetos decorativos queabundaban en las casas de Buenos Aires durante ese período. Ambos elementos fueron entendidos por Ocampo como la representación de una mentalidad que se distanciaba del espíritu contemporáneo. El artículo «La aventura del mueble» testimonia parte de un proceso crítico hacia el desarrollo de una cultura más acorde con su tiempo, iniciado por la misma Ocampo en cuestiones arquitectónicas ya en 1927, momento en el cual pone a esta disciplina al centro del debate en lo que respecta a la representación de una sociedad moderna. Por este motivo, Ocampo no solo se ocupa de arquitectura contemporánea, la cual se mueve descontextualizada de la herencia estética de los "Luises" de los siglos anteriores, sino que también establece una relación en la cual la crítica de arte se impone como reflexión para construir el pensamiento moderno.

Este es el contexto en el cual un grupo de intelectuales instaura una serie de estrategias, entre ensayos y conferencias, mediante las cuales se intenta desarrollar la sensibilidad local para comprender las manifestaciones culturales de los nuevos tiempos. La intención, es aquella de iniciar a definir un canon estético compartido por la sociedad argentina, madurado de la reflexión y la cultura de los propios orígenes. Esta era la posición que compartía de manera latente y manifiesta un grupo de escritores y de artistas que entendían la cultura como una actividad específica de los intelectuales,

1 V. OCAMPO, «La aventura del mueble», Sur, N¹, 1931, pp. 166-174. 
y el arte, como la manifestación superior de ella, siendo intrínseca a la propia identidad.

Dado el momento de prosperidad económica en Argentina del inicio del Novecientos y en particular de la ciudad de Buenos Aires, el país sudamericano afrontaba un gran crecimiento debido también al fuerte componente inmigratorio ${ }^{2}$. Estos factores, unidos al ascenso de una elite económica que replicaba los gestos culturales del contexto de proveniencia trasladándolos sin considerar la falta de continuidad entre el nuevo territorio y los propios orígenes, generaba un collage estético que evidenciaba la necesidad de construir una identidad estética autóctona.

La concomitancia de estos factores genera una situación que se puede interpretar como el inicio de un proceso para escapar de un posible deterioro social,el cual tiene origen en la falta de una significativa sociedad erudita que pueda expresar la creatividad local como testimonio vivo de la propia historia. Los nuevos mecenas, exigentes y ligados a la estética de la academia europea, generalmente apreciaban el arte que reproducía los cánones europeos ya consolidados y que, sin embargo, luego de las nuevas propuestas de las vanguardias resultaban obsoletos, o como mínimo, necesitaban ser evaluados de acuerdo al contexto.

Todos estos elementos se analizarán a partir de una serie de eventos reconstruidos mediante el estudio de la correspondencia de Victoria Ocampo y sus interlocutores, principal documentación recuperada en distintos $\operatorname{archivos}^{3}$, así como mediante el material autobiográfico y los artículos publicados en la revista Sur. De dicho análisis se evidencia como un grupo de intelectuales argentinos participan activamente en el ámbito cultural, impulsados por la necesidad de una profunda renovación estética con la intencion de desarrollar una identidad artística "en sus orígenes", redefiniendo el vínculo con el pasado y propiciando una herencia para el desarrollo futuro. El material de estudio es al mismo tiempo un fiel testimonio de cuanto difi-

\footnotetext{
2 Si bien no es la intencion de este trabajo tratar cuestiones inmigratorias, es necesario considerar este fenómeno como punto desde el cual se articulan las oscilaciones de identidad en Latinoamérica y en particular modo en Argentina, donde es notable la carencia de tradiciones culturales sólidamente mantenidas luego de la colonización. Se puede consultar: América Latina en sus artes, D. BAYÓN (coord.), Unesco - Siglo XXI editores, México D.F., 1974.

3 La Academia Argentina de Letras y La fundacion "Sur" de Buenos Aires, el MART (Museo di Arte Moderna e Contemporánea di Trento e Rovereto), el archivo ASAC (Archivio Storico delle Arti Contemporanee) de Venecia, el archivo de la Triennale di Milano y el Fondo Storico Attilio Rossi, ambos en la capitallombarda.
} 
cultoso fue dicho proceso, en un período en el cual realidad social y el desarrollo de la modernidad se contraponen a los valores de las distintas culturas trasplantadas, por origen y/o por posición social.

Inquietudes y controversias se condensan y articulan en torno a la ya mencionada revista Sur (1931-1992) fundada y dirigida por Victoria Ocampo (Buenos Aires 1890-1979) y su innovativo equipo editorial, que acogía artistas y teóricos de todas las disciplinas, nacionales e internacionales, en el intento de proponer al lector argentino y al ambiente latinoamericano las líneas de pensamiento de mayor trascendencia y calidad, desde una perspectiva interdisciplinaria e intercontinental. Desde esta perspectiva, se entendía reinterpretar los propios orígenes europeísticos.

\section{EI conflicto con el pasado}

La arquitectura de un territorio implícitamente testimonia "un mensaje espiritual del pasado", sin embargo, la homogeneidad de la cual deriva un principio común de origen que determina la propia identidad, no estaba presente en la materialización de la ciudad de Buenos Aires. Proyectada principalmente por arquitectos europeos, en la ciudad colonial se superponen los edificios de programa institucional, construidos por profesionales y artesanos italianos, a las viviendas privadas, muchas de ellas destinadas al alquiler y encargadas a los colegasfranceses.

Es así que la transformación urbana ${ }^{5}$ de Buenos Aires deviene una "citación” europeizante que, sin embargo, no contenía el espíritu cultural que generaba tal nostalgia. Mencionado precedentemente, Argentina del inicio del Novecientos atravesaba un ciclo de relativa estabilidad política y prosperidad económica. Durante este período se produce un enriquecimiento individual y colectivo sin precedentes que abre la puerta a la inmigración masiva que desde España e Italia se aprovecha al máximo. El traslado concentrado hacia la ciudad rioplatense hace que en pocotiem-

\footnotetext{
4 Carta internacional sobre la conservación y la restauración de monumentos y sitios, II Congreso Internacional de Arquitectos y de Técnicos de Monumentos Históricos,reunido en Venecia del 25 al 31 de mayo de 1964.

5 Para conocer más acerca de este proceso, véase: L. CONTRERAS, «Historia cronológica de la ciudad de Buenos Aires 1536-2014», Editorial Dunken, Buenos Aires, 2014.
} 
po esta se consolide como el corazón del sistema bancario, así como sede del gobierno gracias a su actividad portuaria, convirtiéndose en el punto de apoyo del comercio nacional e internacional. La ciudad se transmuta rápidamente en la capital moderna y cosmopolita de un país que irrumpe en la escena internacional, ocupando un lugar privilegiado. Así también lo son los Ocampo, propietarios de grandes extensiones de tierra, son una de las familias más ricas y distinguidas delpaís.

Si a nivel estatal se promovieron fuertes iniciativas para el desarrollo económico y la clase dirigente se concentró en el consumo y la especulación comercial de las tierras, las cuestiones culturales quedaron relegadas a un rol secundario. Por este motivo, a tomar la iniciativa serán las iniciativas articuladas en distintas asociaciones que dividen la ciudad entre "clásica y moderna". Durante el desarrollo de Buenos Aires, la tendencia de la clase dominante esta concentrada en mantener el control de las exportaciones y reproducir los gestos estéticos e ideológicos del academicismo europeo, sin considerar que muchos ya habían sido superados.

Al lenguaje de la arquitectura, se habían incorporado nuevas terminologías: estandarización, funcionalidad, "machine á habiter" , etc. La idea de ornamentación, asume una dimensión diversa, relacionando la belleza no solamente a su morfología agraciada sino a la estética de su funcionalidad. Los tiempos modernos dejan obsoletas las molduras y las decoraciones excesivas, sin embargo son aún la parte imperante del imaginario estético de la gran burguesía argentina, que opta por el neoclasicismo francés como símbolo de estatus y cultura refinada, prefiriendo alejarse de las nuevas fronteras de la arquitectura $^{8}$ que, como disciplina, ahora integra a su morfología cuestiones sociales.

Es evidente que muchas inquietudes se extendieron a otros ámbitos más allá de lo estético y que se hizo urgente la necesidad de encontrar una propia expresión

\footnotetext{
6 En 1938 Francisco Poblet funda la librería Clásica y Moderna, punto de encuentro de artistas, políticos e intelectuales hasta su reciente cierre en febrero del 2019. Librería, café literario y espacio cultural, testimonia con su nombre el espiritu y el modo continuo en el cual se podía percibir Buenos Aires. En 1998 habia sido declarada Sitio de interés cultural por la Legislatura de la Ciudad de Buenos Aires.

7 Con esta expresión, inaugurada por el arquitecto suizo-francés Charles-Édouard Jeanneret, noto como Le Corbusier, se enfatizaba el valor funcional de las construcciones, proclamando la belleza practica y racional de las formas geométricas elementales.

8 En este breve estudio nos centramos en individuar los elementos que nos permiten reconstruir los los hechos. Para mas información sobre las preferencias arquitectónicas de la burguesía argentina: B. SARLO, La maquina cultural. Maestras, traductores y vanguardistas, Siglo XXI Editores, Buenos Aires, 2017, p. 115.
} 
cultural, coherente con su tiempo y en grado de testimoniar la identidad argentina. Dentro de esta nueva reformulación, se introduce la figura de Victoria Ocampo; intelectual, escritora y traductora, que fundó, financió y dirigió la revista Sur, definida por Alejandro Patat, como la operación intelectual más impresionante del siglo XX en América Latina9. Comprometida con su tiempo y sus orígenes "americanos" con epicentro europeo, mediante la publicación de Sur se pueden constatar dos tendencias. En primer lugar, se trata de difundir la cultura entre los distintos estratos sociales, traduciendo todo el material al español como estrategia de unificación, dando a conocer los nuevos lineamientos estéticos de la literatura, las artes plásticas y del espectáculo de mayor trascendencia internacional. En segundo lugar, se busca promover al exterior las nuevas producciones intelectuales locales y generar un flujo bilateral de conocimientos. Tras estos elementales propósitos, había otros menos evidentes, de carácter político con los que se pretendía la renovación social, es decir, generar una serie de reflexiones que permitieran unificar la sociedad argentina ${ }^{10}$ en un proyecto de restauración cultural, como proceso para superar la inercia del clima intelectua ${ }^{11} \mathrm{y}$ transformarse en un polo cosmopolita a la par de las grandes capitales culturales europeas.

Sur no es solo una revista, es más bien el espacio que Victoria Ocampo ofrece para apoyar y promover diferentes pensadores, locales e internacionales, dentro de la cultura contemporánea. Sus páginas fueron pensadas para acoger cruces entre literatura, música, cine y artes plásticas en sus más de cuarenta años de publicación. Entre sus artículos y ensayos se articula una parte primordial del espíritu nuevo que impera en determinados ámbitos intelectuales. Mediante ellos, se actúan progresivas estrategias para rescatar la potencialidad estética argentina utilizando las herramientas de la modernidad y así iniciar a reconocer el propio patrimonio cultural.

Durante este período comienza un proceso que consolida una oligarquía progresista y una clase intelectual atípica, en la cual Victoria Ocampo aparece como

\footnotetext{
9 A. PATAT, Un destino sudamericano. La letteratura italiana in Argentina (1910-1970), Guerra, Perugia, 2005, p. 109.

10 Por ésto tambien es muy importante que la revista haya traducido todo el material publicado al español. Sibien la voluptuosa aristocracia argentina era francófona y anglófona, con lo cual, en grado de leer los textos originales, si la revista mantenía la diversidad lingüística no unificaría el territorio ni los niveles sociales.

11 Ortega y Gasset a partir del 1916 realizó una serie de conferencia en Buenos Aires a partir de que se centraban en la necesidad de instruir el grande publico. Se Visitas culturales en la Argentina. 1898-1936, P. BRUNO (coord.), Editorial Biblos, Buenos Aires, 2014.
} 
una de las principales animadoras. Si bien la relación con la tradición es fundamental durante este proceso, dado que no se entiende hacer un quiebre, sino un cambio, dos líneas generales resumen las principales tendencias que a principios de la década del '20 intentaron imponerse. Por una parte, estaba la continuidad estética vinculada a una mentalidad conservadora y a una tradición académica tanto consagrada como heredada de Europa, la cual en ausencia de experiencias históricas compartidas, se redujo a reproducir una serie de convencionalismos compuestos y basados en la nostalgia por los valores del viejo continente; por otra parte, se pretendía construir una identidad que recuperase la heterogeneidad cultural debida a la inmigración que caracterizaba el país. Sin embargo, era necesario no descuidar los aspectos característicos propios generados en el lugar y que pretendían ofrecer una dimensión estética, en armonía con las enseñanzas y experiencias europeas.

Entre la inmigración, el fuerte componente italiano parece ser uno de los elementos que permitirá amalgamar las cuestiones sociales a las variables estéticas, uniendo el nuevo espíritu creativo al consenso social. La presencia "Bel Paese" es físicamente doble, no solo por la cantidad de italianos presentes en el territorio, sino también por la construcción de muchos de sus edificios ${ }^{12}$, los cuales generan una fuerte persuasión ideológica y de sociabilidad. De hecho, siendo que la arquitectura italiana en Argentina tiene largos antecedentes, la inclinación de Ocampo hacia el arquitecto Alberto Sartoris puede no resultar una novedad, sin embargo, lo que aparece innovativo es el modo mediante el cual la elección estética viene actuada. Por lo cual es necesario considerar los precedentes tentativos de proponer la arquitectura moderna en el contexto porteño ${ }^{13}$.

En 1929 llega a Buenos Aires Le Corbusier, invitado a dar una serie de conferencias y presentar sus proyectos. Si bien uno de los motivos principales era realizar un casa para Victoria Ocampo, las conferencias abarcaron temas de urbanismo, entre los cuales una nueva "poética de planificación” para Buenos Aires ${ }^{14}$. Sin embargo, las

\footnotetext{
12 Véase:M.S. Sabugo, S.TUZI, Contributi italianiall Architettura Argentina/Aportes italianos a la Arquitectura Argentina.ProgettieoperetrailXIXeilXXsecolo/Proyectos yobras en los siglos XIXYXX, Dei Tipografia del Genio Civile, Roma, 2013.

13 Si bien su origen está vinculado con la cercanía al puerto, en Argentina la palabra porteño se utiliza para identificar a los habitantes de la ciudad de Buenos Aires en contraposición con aquellos de la provincia, definidos bonaerenses.

14 Se puede consultar J.F. LIERNUR, E P.PSCHEPIURCA, La red austral. Obras y proyectos de Le Corbusier y sus discípulos en Argentina (1924-1965), EditorialUniversidad Nacional de Quilmes, Buenos Aires, 2012.
} 
propuestas arquitectónicas de Le Corbusier no tuvieron una gran repercusión. Este hecho, estudiado en profundidad por Ramón Gutiérrez, Jorge Liernur y Eduardo Maestripieri, generó titubeos respecto a la posibilidad real de "importar" un arquitecto europeo para que construyera en "estilo moderno" complaciendo el gusto argentino. La resistencia cultural de la elite que podía financiar los proyectos de mayor envergadura, se manifiesta entre indiferente y aprehensiva a ciertos discursos, con lo cual el impacto social de la visita del creador de Ronchamp tuvo mucho menos éxito de cuanto se esperaba, abriendo nuevas cuestiones respecto a cómo proponer la arquitectura moderna en Buenos Aires.

La convicción de Victoria Ocampo estaba motivada en construir un vínculo común entre el territorio y la cultura particularmente heterogénea sin subestimar las cuestiones estéticas de la nueva arquitectura. De hecho esta prerrogativa es determinante (como se verá al afrontar el tema del cine) no solo desde su morfología, sino desde la concepción ideológica que está detrás de las nuevas formas; la "claridad de pensamiento" se vigoriza en la falta de tradición secular que será interpretada como una oportunidad para autodefinirse dentro del contexto moderno y crear una identidad argentina de la cual apropiarse.

Más allá de las variables tecnológicas, construir "alla vecchia maniera" de los estilos europeos no representaba los orígenes de un país "nuevo" como la Argentina. Sin embargo, esta fue la variable mas considerada e impulsada en la construcción por el estado, en contraposición con otros países “jóvenes” como Brasil, Venezuela o el limítrofe Chile que concedieron al lenguaje moderno varios proyectos.

Evidentemente los proyectos de renovación urbana debían partir de iniciativas privadas. Por este motivo Victoria Ocampo había probado proponer una construcción que siguiera los presupuestos de la arquitectura moderna en modo independiente, no solo financiando el proyecto, sino que también ella misma había hecho los croquis con los cuales un constructor edificó la casa: se trataba de una vivienda ubicada en Mar del Plata en la cual Ocampo se dedicaba a sus lecturas. El impacto de la construcción fue tal, entre críticas y burlas, que luego de ser vendida fue inmediatamente demolida por sus nuevos propietarios en 1927. 
Un año mas tarde, esta vez en Buenos Aires, Ocampo vuelve a proyectar su casa siguiendo el mismo estilo. Volumetrías puras y blancas que esta vez hace construir por el arquitecto argentino Alejandro Bustillo, proyectista consolidado de la alta burguesía local, a la cual ambos pertenecían. Sin embargo, Bustillo construye pero no firma el proyecto con la clásica "placa" que generalmente distinguía a sus obras porque no comparte los lineamentos de la arquitectura moderna impuestos por su cliente. Si bien en 1929 durante sus conferencias Le Corbusier elogiará el proyecto de Ocampo y el aporte de Bustillo, el arquitecto argentino mantendrá su estilo neoclásico francés y no se surgirán grandes comitentes interesados a la arquitectura moderna.

Junto a Victoria Ocampo, Sur sigue trabajando. Entre otros, son parte activa de la revista a nivel local: Jorge Luis Borges, Guillermo de Torre, Maria Rosa Oliver y Eduardo Mallea. Desde el extranjero colaboran José Ortega y Gasset, Leo Ferrero, Waldo Frank, Ernest Ansermet, Drieu La Rochelle, etc. La revista publica artículos del muy admirado por Ocampo, Walter Gropius, a quién ella atribuirá su afinidad por la arquitectura moderna debida a los presupuestos del Bauhaus que obviamente mete en relación con los de Le Corbusier.

La realidad demostraba que era necesario re-elaborar el gusto para que un nuevo canon pudiera ser aceptado. Europa, digamos la vieja Europa, sigue siendo el punto de referencia para la mayoría. Sin embargo, los acontecimientos políticos del viejo continente acercan nuevas perspectivas y llega a Buenos Aires una inmigración que no solo busca escapar de la angustia económica, sino también de la creativa.

\section{El desarrollo de la crítica de arte}

Para entender la posición adoptada por Victoria Ocampo, antes que nada, es necesario considerar que hay una estrategia que se despliega en dos niveles que se relacionan transversalmente y dentro de los cuales hay que ubicar los razonamientos fundamentales que incidieron en el intento de construcción del patrimonio cultural argentino. Si la intención era definir una identidad local, durante la década del 30 
se promocionaron distintas teorías creativas y se trató de generar las mejores condiciones para su difusión. El primer aspecto será proponer un modelo material que ponga en relación el público con el "conocimiento directo" y sucesivamente para que dicho "modelo-imagen" funcione, se lo presenta descodificado a los lectores en modo de transformarlo próximo y coherente a las expectativas de los propios orígenes. Sin embargo, para que la imagen efectivamente funcionara como nexo, era necesario reconocerla, presentarla y promocionarla. De alguna manera "traducirla".

Esto conlleva a que contemporáneamente a los modelos propuestos por Ocampo, entendidos casi como "prototipos", la crítica de Sur se mueva en modo instrumental tratando de formar el gusto del público-lector. En este contexto interviene Attilio Rossi (Albairate, 1909 - Milano, 1994) que integra el equipo de la revista como crítico de arte. Sin embrago, su presencia va más allá de este rol y da cuerpo al espíritu italiano presente en la revista en lo respecta a las artes plásticas y visuales. Si bien la crítica de arte haya estado presente en Sur desde el primer número que inauguraba el verano de 1931, sólo desde 1936 es posible identificar, en coincidencia con la colaboración de Rossi, la evidente línea instructiva-pedagógica de la revista.

La figura de Rossi es completa y complementaria a la realidad de Buenos Aires. Nacido en la provincia de Milán llega a la Argentina en 1935, dos años después de haber fundado la revista Campo Gráfico (1933-1939) conocida por haber puesto en relación "la estética de la técnica". Sin embargo, después de los contrastes ideológicos debidos al fascismo imperante, parte desde Italia para realizar un proyecto editorial similar desde la otra parte del Atlántico. En Buenos Aires, conoce al escritor argentino Eduardo Mallea e inmediatamente comienza a colaborar con Sur también gracias a un amigo en común: Cesare Zavattini, guionista del neorrealismo italiano.

Rossi rápidamente trasciende como un personaje ecléctico y encarna el nuevo imaginario europeo: se ocupa de tipografía y se dedica a la pintura, se interesa por el arte y la arquitectura contemporánea. En enero de 1936, en correspondencia con el número 16, escribe para Sur «Enseñanzas de un film»; una reseña que no pasa desapercibida sobre la película española La traviesa molinera dirigida por Harry D'Abbadie D’Arrast y Ricardo Soriano en 1934. La crítica de Rossi trata las expresiones artísticas 
en el sentido más amplio posible; interrelacionándolas, apunta a la “deslegitimación” del sistema crítico oficial altamente académico y se dedica a apoyar los artistas emergentes, en particular aquellos que se habían formado en Italia. Sus artículos, que se publicarán durante dos años consecutivos y prácticamente en cada número de la revista, permiten reconstruir no solo la evolución de la crítica de arte en Argentina, sino también el proceso mediante el cual se actualiza una estrategia de formación del gusto, suscitando contradicciones y controversias. En algunos de sus textos, de alguna manera se sugiere (aunque no lo explique claramente) que la notoriedad de muchos artistas argentinos se debe al mundo corrupto de la crítica local y no al talento real, enfatizando la falta de mutación de los lenguajes y la evolución de la técnica de ciertas obras. A través de gran parte de sus artículos en Sur, deja constancia de su postura respecto a cuanto fundamental sea el conocimiento de la historia del arte, la cual interpreta como una serie de eventos internos y externos a la cultura visual que afectan el nacimiento de nuevas formas. Su mirada se centrará en el aspecto estético de la obra, alternando diferentes perspectivas: por un lado, empujando hacia la integración del valor plástico en cualquier expresión artística y por el otro, desvinculándose de la tradición académica, exaltando la belleza de los valores contemporáneos.

La participación de Rossi en Sur no solo rompe la continuidad del artistacrítico local sino que da regularidad a la publicación de los ensayos sobre la crítica de arte y a su vez define los instrumentos de interpretación ente la obra y el público; la misma que entendía Victoria Ocampo cuando enfatiza los elementos de contemporaneidad de las distintas disciplinas artísticas. En su manera de afrontar la crítica de arte, los artículos de Rossi tienen un espíritu más bien de curador que de mediador. Su rol implícitamente lo estigmatiza como portador de la nueva sensibilidad artística italiana y su presencia se articula entorno al conocimiento teórico implícito en su "natura" europea y aquel madurado por la experiencia práctica. Ambos elementos dan unidad a una figura que opera en los intersticios de la falta de referencias del panorama intelectual argentino. Rossi, tanto como Sur, está convencido de que es necesario conocer la historia y comprometerse con el lenguaje contemporáneo para alentar a los artistas más jóvenes, capaces de generar una relación entre los nuevos movimientos de vanguardia y los propios orígenes. Al mismo tiempo se enfatiza el hecho de que las buenas intenciones no tienen un valor específico hasta que no se traducen en un objeto. 
De la mano de Rossi, la evolución de la crítica de arte y su función pedagógica hacia el despertar del gusto nacional, involucraba al menos dos problemas: por un lado, la capacidad del milanés de interpretar la realidad artística argentina y por el otro, generar el espacio donde la figura del crítico de arte sea considerada un punto de referencia, sobre todo para la élite porteña.

Mediante la figura de Rossi, no solo se redefine la modalidad de la crítica sino también el rol de "especialista". No habiéndose formado en el contexto literario $^{15}$, sus artículos tienden a convertirse en un elemento preciso de selección y descarte de las nuevas propuestas estéticas, específicamente dentro de la pintura, el cine y la arquitectura. Su tono intransigente inaugura en el panorama porteño la "crítica militante". Las ironías de Borges respecto al cine y las reflexiones de Ocampo sobre el estado general de cultura en Argentina, se ven renovadas con el aporte de Rossi que no solo se desempeña como crítico, sino que también organiza exposiciones y realiza muestras de sus propios trabajos, ampliando su campo de "batalla". Es así que propicia la llegada de las obras de Lucio Fontana y otros pintores italianos de vanguardia a Buenos Aires que comentará en 1937 en el ensayo «Primera exposición de dibujos y grabados abstractos en la Galería Moody»: artículo que se refiere a una muestra realizada en dicha galería de Buenos Aires donde él no solo es el crítico de arte, sino que también será el curador de la exposición.

Después de un período de artículos y "obras” de pequeña escala como las muestras y las exposiciones, se hace necesario cambiar la magnitud del impacto del arte e intervenir en el espacio urbano. La idea era iniciar a materializar los vínculos que pudieran testimoniar el origen del patrimonio local. A partir de esta nueva posición, orientar el gusto local debe ir más allá de la predisposición del lector, con lo cual se da comienzo a un trabajo de orientación del "público". Rossi, basándose en su contacto con los protagonistas de los grandes movimientos de vanguardia en Italia, trata de acercar el lector-público argentino a la experiencia directa de vivir en el propio contexto los nuevos lenguajes artísticos plasmados in loco. De este modo, superpone a las condiciones naturales los elementos de la creatividad moderna y combina su papel de crítico con el de mediador, que no mete en relación la obra de arte, sino la

15 Mientras que la relación entre la literatura y el cine comenzaba a ser explícita, el escritor comenzó a tener un alcance más amplio, imponiéndose como una figura profesional perteneciente al mundo contemporáneo. 
experiencia estética que proviene del contacto con los artistas de hibridación ítaloargentina, en particular Emilio Pettoruti y Lucio Fontana. En esta síntesis se confirma la vocación didáctica con la que Sur, usualmente entendió la tarea de la crítica de arte y que Attilio Rossi había definido claramente en términos de un discurso conceptual preciso.

El discurso se transformará en objeto, o al menos eso pretende. En Buenos Aires durante 1936, Rossi intenta reintroducir al escultor Lucio Fontana (Rosario 1899 - Comabbio 1968) en el ambiente cultural argentino. De padres italianos, Fontana había nacido en la provincia Argentina de Santa Fe, y sucesivamente había sido enviado a Italia, donde creció y estudió. Fontana y Rossi se habían conocido en Milan y su amistad se remonta a la prima monografía sobre el futuro creador del «Manifiesto Blanco» dado que había sido publicada por la revista Campo Gráfico en 1936, realizada por Edoardo Persico y compagina por Rossi. La amistad entre ambos artistas se transforma en colaboración profesional y desde Buenos Aires, Rossi continúa animando el espíritu artístico italiano presente en Argentina e intenta realizar una obra con la participación de Fontana en el concurso organizado por la ciudad de Buenos Aires para la construcción del monumento ecuestre en homenaje al general Simon Bolivar.

Como testimonian los documentos encontrados en los respectivos archivos, la participación de Rossi es estratégica, dado que se encarga de enviar a Italia las bases del concurso, explicando a sus colaboradores las relaciones con el emplazamiento y las restricciones del código de urbanismo. Por su parte, Fontana en Milán involucra al arquitecto italiano Luciano Baldessari para componer un proyecto más completo e integrado con el entorno y con el apoyo de Rossi se presentan con el proyecto Pampas.

Pese a que la obra no fue seleccionada por la Comisión y más adelante sus autores dejarán en el olvido los croquis y las maquetas, el compromiso de Rossi representó el esfuerzo extremo que trata de crear la oportunidad de definir una especie de "quórum estético" presentando un prototipo artístico a gran escala con el cual tanto el público como el lector podían hacer referencia. No obstante el resultado del concurso, Rossi permanece concentrado en la alianza estratégica entre las diferentes 
disciplinas y en la cooperación creativa entre Italia y Argentina, ya que había intuido que un trabajo de horizontes compartidos era una oportunidad de reconocimiento dentro de la escena cultural local e internacional. Establecido en Argentina, Rossi es consciente de la necesidad de gravitar alrededor de las metrópolis culturales europeas, por un lado, porque era una de las premisas de Sur ante la necesidad de interrumpir la recesión creativa local y por el otro, porque era claro que el gusto porteño era el reflejo del gusto consagrado en Europa.

Rossi seguirá en Argentina hasta 1951, momento en el cual vuelve a Milán y se radica definitivamente en Italia. Después de su colaboración en Sur, participa en el proyecto editorial Austral, que Gonzalo Losada, director de Espasa-Calpe Argentina, encargó a Guillermo de Torre que a su vez pensó para el diseño del logo y delas cubiertas de los libros en Attilio Rossi, esta vez en el rol de artista y diseñador.

\section{La construcción de la propia identidad: la arquitectura}

Al interesarse por un modelo estético definido conscientemente, Victoria Ocampo ve en la arquitectura racionalista de la década de los 30, los indicios de una nueva posibilidad cultural para su país. Si la arquitectura debe considerarse como el reflejo de los logros técnicos y culturales de la sociedad, entonces se podría decir que Victoria Ocampo fue una de las precursoras en comprender la arquitectura como patrimonio cultural al tratar de delinear un vínculo entre la comunidad y la identidad contemporánea. Esta interpretación se basa en el análisis de los amplios intereses de Ocampo. Su innovativa perspectiva anticipa el actual rol del Cultural Manager personalizando el modo a través del cual construye su red de relaciones en el intento de desarrollar las potencialidades locales, interpretando la producción artística como la mayor expresión cultural de una sociedad.

En 1935, llega a Buenos Aires por invitación del Instituto Argentino de Cultura Itálica, el arquitecto italiano emigrado en Suiza, Alberto Sartoris (Torino 1901-Pompaples 1998) para dar una serie de conferencias sobre la arquitectura y la estética moderna. Si se compara lo que habia sucedido en la visita de Le Corbusier, la larga lista y el carácter de las sedes que acogen las conferencias de Sartoris, testimonia 
no solo la natural predisposición argentina hacia Italia, sino que también expresa la creciente apertura cultural hacia los diferentes ámbitos artísticos, seguramente madurada en los cinco años que separan ambos eventos.

Durante su estancia en Buenos Aires, Sartoris demuestra ser un interesante teórico de la arquitectura y dotado de una notable erudición respecto a los diversos movimientos de vanguardia artística. En sus conferencias, insinúa que una adecuada lectura de la nueva arquitectura podría ser la clave para construir los vínculos entre la sociedad y el territorio.

La bibliografía específica sobre el tema es prácticamente nula, pero es lógico pensar que fueron las relaciones personales las que introdujeron al arquitecto italiano en el entorno de Sur. Si se consideran las precedentes experiencias en cuanto a la predisposición hacia la arquitectura moderna de la directora de la revista, no resulta extraño que en 1936 aparezcan nuevos indicios respecto a su intención de realizar un nuevo proyecto de renovación edilicia que ve en el racionalismo italiano una alternativa factible para la Argentina. Sartoris se acerca a Ocampo con dos cartas de presentación ganadoras: en primer lugar, la amistad que lo une al pintor argentino Emilio Pettorutti (La Plata, 1892 - Paris, 1971), representante de la vanguardia europea en Argentina, del cual Sartoris fue su principal propulsor en el viejo continente, escribiendo la introducción de varias de sus exposiciones. En segundo lugar, está la posición estética e ideológica que comparte con su amigo Rossi, quien a su vez también se había ocupado de la monografía de Sartoris después de publicar la de Fontana. Sin embargo, serán también las páginas de Sur a testimoniar la importancia de la presencia de Sartoris en Buenos Aires y la revista publicará en 1936, dos de sus artículos: «Ideas a la Sordina» ${ }^{16} \mathrm{y}$ "Ajustes a una estética» ${ }^{17}$.

En el primer artículo, que aparece en el número 18 de Sur, mediante el uso de metáforas y fantasías, se puede percibir la personalidad de Sartoris así como su modo de afrontar la arquitectura, donde se destaca el equilibrio con el cual describe meticulosamente la realidad social, desde una percepción poética y especulaciones metafísicas. Más allá del lirismo del texto, Sartoris llega a reconstruir la identidad argentina 
que, si bien no es exhaustiva, está correctamente definida en el interpretar contrastes y diferencias sociales. Al leer la ciudad, reconoce una línea de pensamiento divergente que enmaraña en Buenos Aires y después de algunas observaciones precisas sobre la sociedad y los aspectos ambientales, Sartoris parece querer promover el espíritu de "moderación" frente a las posibilidades arquitectónicas para intervenir sabiamente en la ciudad enfatizando las consecuencias de su impacto. Luego se ocupa de tratar las instituciones como posibles elementos de progreso, especificando que sus iniciativas deben ser conducidas con nobleza hacia la vida pública y privada.

Su segundo artículo, en el número 25 de octubre del mismo año, se publica en Sur conjuntamente con uno de Rossi ${ }^{18}$, reforzando la moderna presencia italiana en la revista. En el ensayo "Ajustes a una estética» el propósito parece ser doble: el primer aspecto que se nota es la predisposición de Sartoris en encontrar una estética que consolide su valor en la calidad cultural del lugar. El segundo aspecto que trasciende son sus explícitas intenciones estrictamente didácticas e informativas dirigidas a generar la continuidad plástica de la estética del racionalismo.

En estos dos ensayos Sartoris aborda el tema de la arquitectura, argumentando que debe proyectarse con convicciones precisas y que en el caso de Argentina, deben responder a su geografía. En el enfatizar la relevancia del espíritu del lugar, contempla las características físicas y sociales que intervienen en el entorno arquitectónico. Todo esto se concentra en presentar la arquitectura moderna como dotada de una coherencia formal e ideológica en línea con el período histórico actual y particularmente adecuada para la joven nación argentina. Coherente con esta línea, Sartoris comienza a diseñar una casa en Buenos Aires para Pettoruti en la ciudad de La Plata, en la cual se evidencian las huellas de la utopía del dibujo inspirados en la ideal purificación de la geometría. El proyecto se publicará en el Tercer volumen del libro «Encyclopedie de l'architecture nouvelle», que estaba terminando durante su viaje en Argentina con el título «Ordre et climat américains»: una colección de proyectos en los que también quiere incluir ejemplos argentinos, como la casa de Ocampo construida por Bustillo.

18 A. ROSSI, «Salón de pintores argentinos en Amigos del arte», Sur, N²5, 1936, pp. 90-100. 
Tanto Sartoris como Ocampo parecen compartir el sentido poético de la arquitectura, que articula a la modernidad la sintaxis de las nuevas tecnologías sin descuidar la identidad del propio espacio. Al concluir su viaje por Buenos Aires Sartoris se dedica al diseño de la casa para Pettoruti. El proyecto en La Plata se transforma en una oportunidad para volver a organizar un viaje del arquitecto italiano a Buenos Aires. La propuesta del entorno de Ocampo, parece también hipnotizar durante la segunda estadía de Sartoris una posible colaboración entre él y Bustillo. El motivo que sostiene este razonamiento es que Victoria Ocampo se confronta con dos cuestiones anteriormente anticipadas que son: la resistencia cultural de "admitir"las ideas propuestas de Le Corbusier porque no se adaptan al gusto de la elite porteña y la falta de interés del arquitecto Bustillo, que guiaba las tendencias estéticas de dicha elite, en considerar las nuevas posibilidades tecnológicas y estéticas de dicha disciplina. Si proponer un lenguaje contemporáneo de la arquitectura, nace de la unión de la conciencia local y las nuevas teorías habitativas, Victoria Ocampo imagina a través de Sartoris una "contaminación" de Bustillo hacia el racionalismo mediante una colaboración entre ambos. Su idea era tratar de "convertir" al arquitecto argentino en el traductor de los parámetros estéticos-constructivos de la arquitectura contemporánea al ambiente local, dando por descontado que si eran propuestos por Bustillo, gurú del gusto porteño en esta disciplina, esto podía dar a Buenos Aires su propio lenguaje y de este modo consolidar un nuevo modelo basado en la originalidad de la interpretación del entorno. Victoria Ocampo intenta evidenciar la transversalidad que converge en la experiencia artística italiana y la necesidad de reformular las propias posiciones. Esto se evidencia en el artículo «Sobre un mal en esta ciudad» que ella misma escribe:

"Y si no lo has hecho hasta ahora, ciudad mía, comprende mi rencor. Veo tus posibilidades. Líbrate para siempre de la tentación de imitar las viejas y magníficas ciudades de Europa, o parecerás eternamente una grotesca caricatura. Otro destino te aguarda. Las ciudades que hoy es posible construir, bañadas en follaje y en sol, tienen una belleza que les es propia, peculiar y que no cambio por ninguna otra. Las viejas ciudades son maravillosas de ver, pero inhabitables como museos" $"$.

19 V. OCAMPO, «Sobre un mal de esta ciudad», Sur, $\mathrm{N}^{\circ} 14,1935$, pp. 104. 
Aunque si el segundo viaje de Sartoris nunca se pudo realizar, el primer viaje se convirtió en un evento que generó nuevas discusiones sobre la identidad arquitectónica argentina y las posibilidades de iniciar a construir su patrimonio cultural. Luego de diversos proyectos que no llegaron a concretarse, Victoria Ocampo se concentrará en apoyar el arquitecto argentino Alberto Prebish y difundir sus proyectos y teorías entre las paginas de Sur.

\section{La battuta final un documental sobre La Pampa}

Durante la opulencia del inicio del Novecientos en Argentina, si se comparaba Buenos Aires con algunas de las ciudades internacionales más prestigiosas, el resultado podía ser reconfortante desde varios puntos de vista. Sin embargo, al mismo tiempo esta comparación evidenciaba lo que Buenos Aires no era y lo que la ciudad no tenía: una tradición secular que sirviera de inspiración para consolidar una expresión cultural propia y generar una propuesta estéticamente interesante con el objetivo de mezclar el pasado con las tendencias de vanguardia.

En este contexto, el cine podría representar para Buenos Aires la posibilidad concreta de generar su propia expresión artística capaz de encontrar en la imaginación cierto grado de independencia estética e innovación creativa. Victoria Ocampo ve en el cine, que se estaba haciendo espacio entre las categorías artísticas, la posibilidad de dar a conocer la potencialidad creativa del ambiente argentino con su consiguiente difusión en el ámbito internacional, acercando el propio país a los iconos más importantes del cine de la época. Si el cine se podía considerar como el "recién llegado" entre las categorías artísticas, entonces incluso la "recién llegada" entre lascapitales culturales podía aspirar a ocupar un lugar dentro de las metrópolis internacionales, a través de la creación de su propio lenguaje fílmico.

De la correspondencia de Victoria Ocampo presente en los archivos de Harvard, se analizaron las cartas entre la directora de Sur y el cineasta Sergej Ėjzenštejn (Letonia 1898 - Moscú 1948) que inicia luego de su primer encuentro en Nueva York. En 1930 Victoria Ocampo viajó a los Estados Unidos por primera vez para reunirse con su amigo, el escritor Waldo Frank (New Jersey 1889 - New York1967) 
fundador y director de la revista Seven Arts. El objetivo del viaje era definir los problemas organizativos relacionados con el lanzamiento inminente del primer número de la nueva revista: Sur. El viaje, comentado ampliamente por la misma Ocampo, está lleno de anécdotas respecto a la ciudad y a los personajes que encuentra, quedando en segundo lugar los argumentos sobre la revista, sobre todo debido al encuentro inesperado con el cineasta sovietico Ėjzenštejn. Si bien Ocampo conocía su trabajo y admiraba los planteamientos teóricos, la innovación cinematográfica que planteaba Ėjzenštejn mediante la concatenación de fragmentos sin conexión aparente, generaba para Ocampo una experiencia estética a través del montaje creativo dado del intelecto. Durante el viaje, la personalidad de Ėjzenštejn eclipsa la revista e la inspira a realizar un proyecto documental en Argentina con este nuevo amigo como director. De hecho entre ambos nace una sincera amistad, al punto que Ėjzenštejn se convertirá en una figura citada de forma recurrente en muchos escritos de Ocampo.

De hecho, la primera referencia hacia Ejzenštejn surge, con cierta perplejidad, en referencia a la película de Robert Flaherty Man of Aran (1934). En el número 10 de julio de 1935, Sur publica el ensayo de Victoria Ocampo, «Sobre El Hombre de Aran». Esta es la primera vez en la cual Victoria Ocampo se ocupa personalmente de cine en la propia revista. El ensayo propone con autoridad conceptual una nueva lectura de las posibles relaciones entre los componentes cinematográficos, dandoun sentido a ciertas imágenes de tomas largas y hasta repetitivas.

La intención fundamental del artículo es aquella de transmitir al público el concepto de "unidad estética", la cual puede ser solamente percibida exagerando o actuando una elección particular de estrategias, que están relacionadas con el film y el especifico director. El mensaje hacia el lector-espectador está motivado por el deseo de definir los criterios estéticos y no afrontar solamente la cuestión del gusto. Por esta razón Ocampo se ocupa personalmente del documental antropológico de Flathery con la clara intención de re-proponer la lectura de la película, enfatizando algunos elementos compositivos que la crítica oficial no habría considerado o les habría dado poca relevancia. Contemporáneamente, dado que la Argentina no se puede permitir grandes producciones al estilo Hollywood, Ocampo quiere transmitir que es posible crear un buen cine a través de la creatividad propia del lenguaje cinematográfico a 
partir de experiencias reales sin deber recurrir necesariamente a costos elevados. Este es el punto en el cual el montaje propuesto por Ėjzenštejn deviene en un acto creativo decisivo dentro del sistema de producción.

Ocampo no quiere hacer una película cualquiera: quiere hacer un documental sobre La Pampa ${ }^{20}$. Como anticipado, la provincia de La Pampa es también inspiradora del monumento que habían propuesto Fontana y Rossi; es parte del imaginario con el cual Ortega y Gasset se refiere a su amiga, cuando llama Gioconda de La $P a m p a^{21}$ a la fundadora de Sur. Esa extensión horizontal que recorre la Argentina es la que el escritor francés Dieu La Rochelle define delante de Borges como vertigine orizzontale $^{22}$ : naturaleza implícita del Rio de La Plata y de la llanura pampeana en la provincia. En La Pampa, el nombre se transforma en concepto, origen de la propia belleza. Ya no se trata de un lugar sino del espíritu en el cual los argentinos pueden reconocer la propia identidad y por eso se instaura como un elemento desde el cual construir el propio patrimonio cultural. La Pampa, no proviene de Europa, no es una cosa heredada o trasmutada: es la esencia de ser parte de un lugar con límites que parecen infinitos y por eso su presencia es recurrente durante la búsqueda de la propia identidad.

Luego de distintos tentativos, el documental que Ėjzenštejn estaba dispuesto a filmar en Argentina no pudo realizarse por cuestiones económicas, dado que a una gran parte de los posibles financiadores argentinos no les interesaba un director de cine que se pudiera asociar con el comunismo soviético. Esta tentativa que precede el primer número de la revista Sur, no quedará solo en la memoria. Sucesivamente

20 Despues de conocer a Ėjzenštejn, escribe a su hermana Angelica sobre la posibilidad de realizar el proyecto cinematográfico "[...] ya tenemos medio arreglado que después de su film en Hollywood (sale para los Angeles y va a trabajar a Paramount) trataremos de que haga un film argentino, en Argentina, con temas argentinos, podria ser algo estupendo iy qué propaganda mundial nos haría un film de Eisenstein! Por supuesto habría que elegir un tema nacional y mostrar mucho campo”, E. PAZ LESTON, «Victoria Ocampo. Cartas a Angelica y otros», Sudamericana, Buenos Aires, 1997, pp.42.

21 "Ortega, entonces le abrio las puertas del idioma. Ademàs él estaba deslumbrado con esa Gioconda de La Pampa -como la llama en una carta fechada en mayo 1917 en España- de rostro armonioso y divino [...]”, M. E. VÁZQUEZ, «Victoria Ocampo. El mundo como destino», Editorial Victoria Ocampo, Buenos Aires, 2010, pp. 77.

22 "Conocí cuando estuvo en Buenos Aires, a uno de los primeros colaboradores de "Sur", una persona que me impresiono, Pierre Driu La Rochelle, muy inteligente [...] Era un poco tarde y habíamos llegado caminando hasta cerca del limite con la provincia. Se sentía agrandarse la llanura y las casas eran cada vez mas escasas y bajas. Dieu La Rochelle encontró entonces una forma muy precisa para expresar lo que nosotros, los poetas argentinos, buscábamos desde cumpleaños atrás. mirábamos. Era la madrugada. Me dijo “vértigo horizontal'...", J. L. BORGES, dialogo con N. Murat, citado en «Victoria Ocampo, intimidades de una visionaria», L. AYERZA DE CASTILLO, LAURA - O. FELGINE, Editorial Sudamericana, Buenos Aires, 1992. pp. 142. 
la revista se dedica a publicar ensayos y reseñas sobre cine, así como las imágenes del film de Ėjzenštejn ; Que viva Mexico!, película en la cual transpare la fascinación por la compleja cultura popular de ese país sobre el cual había podido aprender muchas cosas durante su estadía, iniciada en diciembre de 1930 hasta enero de 1932.

Volviendo a la Argentina, si el cine representaba la posibilidad de delinear un camino creativo singular era aún necesario examinar nuevamente el propio material; desde lo estético hasta lo ideológico.

Terminado el período del fascismo, a partir de 1951 Victoria Ocampo retoma sus contactos con Italia y repropone el proyecto cinematográfico. Como lo demuestra la correspondencia con Vittorio De Sica e Cesare Zavattini, presente en La Academia Argentina de Letras, serán ellos los encargados de realizar el nuevo film. De Sica le escribirá: "Le assicuro che è ferma la mia intenzione di venire un giorno in Argentina per fare un film laggiù. Mi interessa per le affinità spirituali che legano il popolo Argentino con 1'Italiano"23.

Las palabras de De Sica son significativas por varias razones. En primer lugar, porque evidencian el interés común en crear una coproducción ítalo-argentina, poniendo en resalto una afinidad bilateral. En segundo lugar, nos permite comprender bien la constancia con la cual Ocampo se dedica a su rol de promotora cultural actuando a través de Sur y, sobre todo, permite comprender la dimensión de los distintos tentativos y su evolución para dar a la Nación Argentina la posibilidad de reconocer y apropiarse de su propio espesor cultural. La sucesión de experiencias es fundamental en la búsqueda de la "imagen" del cine argentino que nacía también del contraste con los elementos que caracterizaban la producción local, bastante sombría del momento. Es el período en el cual se pasa al cine sonoro y desde ese momento crece en los argentinos la necesidad de reconocerse en el propio idioma. La repentina urgencia de encontrar sus raíces se consolida y el tango aparece como el elemento que determina la propia identidad, reconocible y estructurante de la imagen, deslizándose hasta transformarse en un cliché fuertemente criticado por aquellos que vieron en el cine una expresión artística y no una parodia. Jorge Luis Borges comentaba “[...]

\footnotetext{
23 Carta de Vittorio de Sica a Victoria Ocampo, Roma, 24 settembre 1956, archivo de la Academia Argentina de las letras, Buenos Aires.
} 
Éste -Los muchachos de antes, etc.- es indudablemente uno de los mejores filmes argentinos que he visto: vale decir, uno de los peores del mundo[... $]^{\text {"24. }}$

La producción cinematográfica local aparece muy pobre si se la comparaba con la europea o la norteamericana de los años '40. Por este motivo el interés de Borges y Victoria Ocampo será crucial para difundir un punto de vista crítico en la percepción de lo que podía ser cine para los argentinos. En un entorno compuesto por varios intelectuales, las posiciones de Borges y Ocampo, si bien muchas veces eran contrapuestas, coincidían sobre todo en promocionar la riqueza del cine como expresión artística local y encontrar posibles caminos para su desarrollo. Reunidos en Sur, la revista dedica un espacio al cine desde su primer número publicado en 1931 y se evidencian desde el inicio al menos dos tendencias: por una parte, se trata de presentar una reseña generalmente realizada por escritores profesionales de las nuevas películas llegadas al país y por otra, se publican ensayos que teorizan la actividad del cine, problemáticas y potencial, plenamente conscientes del valor artístico el cine. Nuevamente se actúa la doble estrategia introducida por Victoria Ocampo precedentemente: por un lado, el análisis del objeto (la proyección del film) y por el otro, los medios para decodificarlo (el ensayo).

Los ensayos escritos por Benjamin Fondane o el mismo Ėjzenštejn (entre tantos otros) proponen una teoría del cine, sin embargo, la difusión de sus ideas no adquiere suficiente fuerza para incentivar una teoría y una producción nacional. Se necesitaba un modelo de identificación colectiva, independiente de los criterios comerciales: un tipo de película que proporcionase un espacio para la mediación entre el lenguaje escrito y el "el idioma de la imagen moviente" ${ }^{25}$ como lo definió Victoria Ocampo en 1950. Nuevamente se presenta la necesidad del prototipo: un modelo que sirva de referencia para la producción nacional superando la habitual retórica caricatural típica de los "argentinos tangueros". Era urgente encontrar la autonomía estética definida al margen de la tendencia a la exageración y la imitación.

A su vez, se hace necesario hacer una película "inaugural" del cine argentino que tienda a la construcción de un modelo, en la convicción de poder encender una 
iniciativa cultural sin precedentes y crear nuevas formas artísticas en el país como testimonio del patrimonio cultural.

Si el primer proyecto ideado con Ėjzenštejn no se pudo hacer por cuestiones económicas, el segundo tentativo imaginado con Vittorio de Sica y Cesare Zavattini tampoco pudo materializarse por cuestiones políticas. El mismo año en el cual Ocampo propone sin éxito a la Comisión de Cultura Argentina realizar una coproducción con Italia, es acusada de conspiración contra el gobierno de Perón e inmediatamente encarcelada a sus 62 años. Sucesivamente y gracias al apoyo internacional de sus amigos, en la Carcel del Buen pastor pasará menos de un mes, luego de que distintos intelectuales, entre los cuales el premio Nobel Gabriela Mistral, dirigen una carta al gobierno exigiendo la libertad de Ocampo, que vendrá excarcelada. Sin embargo, no le será permitido viajar al exterior.

\section{El patrimonio que no fue}

De cuanto brevemente expuesto, que recupera elementos de mi tesis doctoral, se puede observar la búsqueda que iniciaron un grupo de intelectuales con centro en Buenos Aires, para encontrar la propia identidad social, con la intención de dar origen a construir el patrimonio cultural argentino. Una cuestión inmaterial que se sintetiza en este breve trabajo y se afronta desde el desarrollo de la arquitectura, la crítica de arte y el cine. Estos elementos han sido individualizados como esenciales en la construcción de la propia identidad, tratados desde su carácter pedagógico y persuasivo. Los distintos tentativos que se generaron dentro de estas categorías, aparecen hoy como una lista de oportunidades mal aprovechadas y que inevitablemente obliga a interrogarse sobre como hubiese cambiado el panorama cultural un film argentino realizado por Ėjzenštejn, un espacio público con una escultura de Fontana y la misma Buenos Aires con un patrimonio arquitectónico racionalista. 